\title{
The experience performing extended abdominoplasty in massive weight loss patients
}

\author{
Maria A. Bocchiotti, Elisabetta Adelaide Baglioni, Stefano Bruschi, Luca Spaziante, Erind Ruka \\ Department of Reconstructive and Aesthetic Plastic Surgery, Cittadella Salute e dellaScienza Hospital, University of Turin, 10100 Turin, Italy.
}

Correspondence to: Dr. Erind Ruka, Department of Reconstructive and Aesthetic Plastic Surgery, Cittadella Salute e dellaScienza Hospital, University of Turin, 10100 Turin, Italy. E-mail: erind549@hotmail.com

How to cite this article: Bocchiotti MA, Baglioni EA, Bruschi S, Spaziante L, Ruka E. The experience performing extended abdominoplasty in massive weight loss patients. Plast Aesthet Res 2017;4:57-63.

Dr. Erind Ruka is an Italian-Albanian plastic reconstructive and aesthetic plastic surgeon. After finishing his surgical
training at the University of Turin in Turin, Italy, he started working in different countries all across Europe and relocated
in several plastic surgery departments. His main fields of interest are facial aesthetic and reconstructive surgery, breast
aesthetic and reconstructive surgery, wound repair and regenerative medicine. Furthermore, he has published as author
or co-author several papers in national and international scientific journals and acts as reviewer for several plastic
surgery journals.

Article history:

Received: $30-12-2016$

Accepted: 07-04-2017

Published: 21-04-2017

Key words:

Post-bariatric, abdominoplasty, torsoplasty, complications, body contouring, body reshaping

\begin{abstract}
Aim: The post-bariatric patients who undergo torsoplasty often incur postoperative complications that dilate their recovery time. The authors propose the technique of extended abdominoplasty, described in 2012 for aesthetic torso remodeling, in post-bariatric patients in order to reduce complications and hospitalization time. Methods: The authors performed 21 extended abdominoplasties and compared them with 21 torsoplasties in post-bariatric patients during a 1-year period. Data studied was age, gender, duration of the procedure, blood loss, complications and hospitalization duration. Results: Peri and postoperative bleeding led to 3 cases of anemia necessitating blood transfusions in $14.3 \%$ of the second group; no blood transfusion was needed in the first group. No other major complications occurred during the postoperative period in both groups. Conclusion: The authors believe that extended abdominoplasty is a viable alternative to the torsoplasty in selected patients presenting a severe adipocutaneous circumferential laxity, as occurs in post-bariatric patients with a significant weight loss.
\end{abstract}

\section{INTRODUCTION}

In the last years, the prevalence of obesity has increased in most industrialized countries. ${ }^{[1]}$ The rise on obesity prevalence has taken a concomitant increase in bariatric surgery procedures. Moreover, bariatric surgery has demonstrated to improve or even to eradicate significant obesity-related comorbidities including diabetes mellitus, hypertension, dyslipidemia, and obstructive sleepapnea. ${ }^{[2-6]}$ 
Despite the large number of benefits conferred by bariatric surgery, the massive weight loss causes a persistence of a large amount of inelastic skin and subcutaneous tissue, which can lead toskin irritations, mycotic infections and secondary self-imaging problems (potentially a worsened overall patient bodyimage). Skin redundancy following massive weight loss is both an aesthetic and functional problem.

The number of patients demanding plastic surgery correction of contour abnormalities has increased with the advancement in weight loss procedures. Massive weight-loss patients often present a circumferential truncal skin and subcutaneous tissue redundancy, which cannot be optimally corrected by common abdominoplasty techniques. The main issue is the remaining of skin bulges in the flanks and in the dorsal area. When glutealptosis is also present, a $360^{\circ}$ contouring procedure is necessary: in these cases the most frequent operation is torsoplasty. ${ }^{[7]}$

Nevertheless, both circumferential abdominoplasty and torsoplasty have intraoperative and postoperative high risk of complications such as bleeding, anemia, dorsal dehiscence of the surgical wound due to forced supine position, infection, seroma (often posterior ones). ${ }^{[8-10]}$

As an alternative to circumferential abdominoplasty, wedescribeour experience with the extended abdominoplasty technique. ${ }^{[11,12]}$ This technique was first described by Mejia and Cárdenas Castellanos ${ }^{[12]}$ to treat aesthetic deformities of the abdomenin non-bariatric patients and it preserves the median dorsal area from surgical traumas. We extended the indication to the massive weight loss patients. The aim was to reduce postoperative complications and hospitalization time.

\section{METHODS}

\section{Patients}

Twenty-one consecutive patients underwent extended abdominoplasty after bariatric surgery [body mass index (BMI) $\geq 40$ ] between September 2014 and November 2015. Data concerning age, gender, BMI at the time of plastic surgery, weight loss, duration of the procedure, resected tissue weight, perioperative blood loss, duration of hospitalization, follow-up, associated procedures and complications were collected and compared with those of 21 patients who had undergone a classical torsoplasty during the same period.

Patients were selected after passing the following inclusion criteria: severe abdominal and truncal skin
Table 1: Patients characteristics

\begin{tabular}{lcccc}
\hline \multirow{2}{*}{ Characteristics } & \multicolumn{2}{c}{ Extended abdominoplasty } & \multicolumn{2}{c}{ Torsoplasty } \\
\cline { 2 - 5 } & Range & Average & Range & Average \\
\hline Age (years) & $30-63$ & 46.8 & $30-61$ & 45.2 \\
Bariatric BMI & $41-61$ & 51.6 & $42-56$ & 47.5 \\
Post-bariatric BMI & $26-30$ & 28.6 & $25-30$ & 27.3 \\
Weight loss (kg) & $28-115$ & 69.4 & $35-85$ & 61.8 \\
\hline
\end{tabular}

BMI: body mass index

redundancy, circumferential lipodystrophy type VI according to Mejia and Cárdenas Castellanos, ${ }^{[12]}$ unchanged weight during the last year, and age between 30 and 65 years.

Patients were excluded if affected by diabetes or coagulopathies, or if they had undergone prior trunk reshaping procedures were excluded.

Patients' characteristics are described in Table 1.

\section{Planning and marking}

We performed the body contouring procedures after twelve months of stable bodyweight. Liposuction wasn't performed in any case. Photographs were taken preoperatively and postoperatively.

Skin markings are placed preoperatively with the patient in standing position, the day before the procedure, using a method similar to that described by Mejia and Cárdenas Castellanos. ${ }^{[12]}$ The scaris positioned low enough to be easily hidden by the underwear.

Anteriorly, a vertical supra-pubic midline is drawn. The lower point of the resection is 7-8 $\mathrm{cm}$ from the vulvar anterior commeasure or from the base of the penis. Two lateral lines of $7 \mathrm{~cm}$ are drawn from the vertical line, and are then continued to the iliac crests.

Laterally the abdominoplasty line is stretched along the two sides keeping the iliac crest height without reascending [Figure $1 \mathrm{~A}]$. From this line, by pinching, the upper flap of adipocutaneous excess has to be marked along the lateral hip profile. The abdominoplasty superior line has to be stretched until the abovementioned point [Figure 1B].

In the dorsal area, we draw a vertical line positioned in the interspinal line, and then the marking of the upper incision line is extended backwards, almost straight over the gluteal crease, not exceeding it [Figure 1C]. This line is then directed downwards and medially. And by pinching, the inferior line has to be marked in order to correct the glutealptosis [Figure 1D].

Lastly, vertical lines along the entire drawing have to 

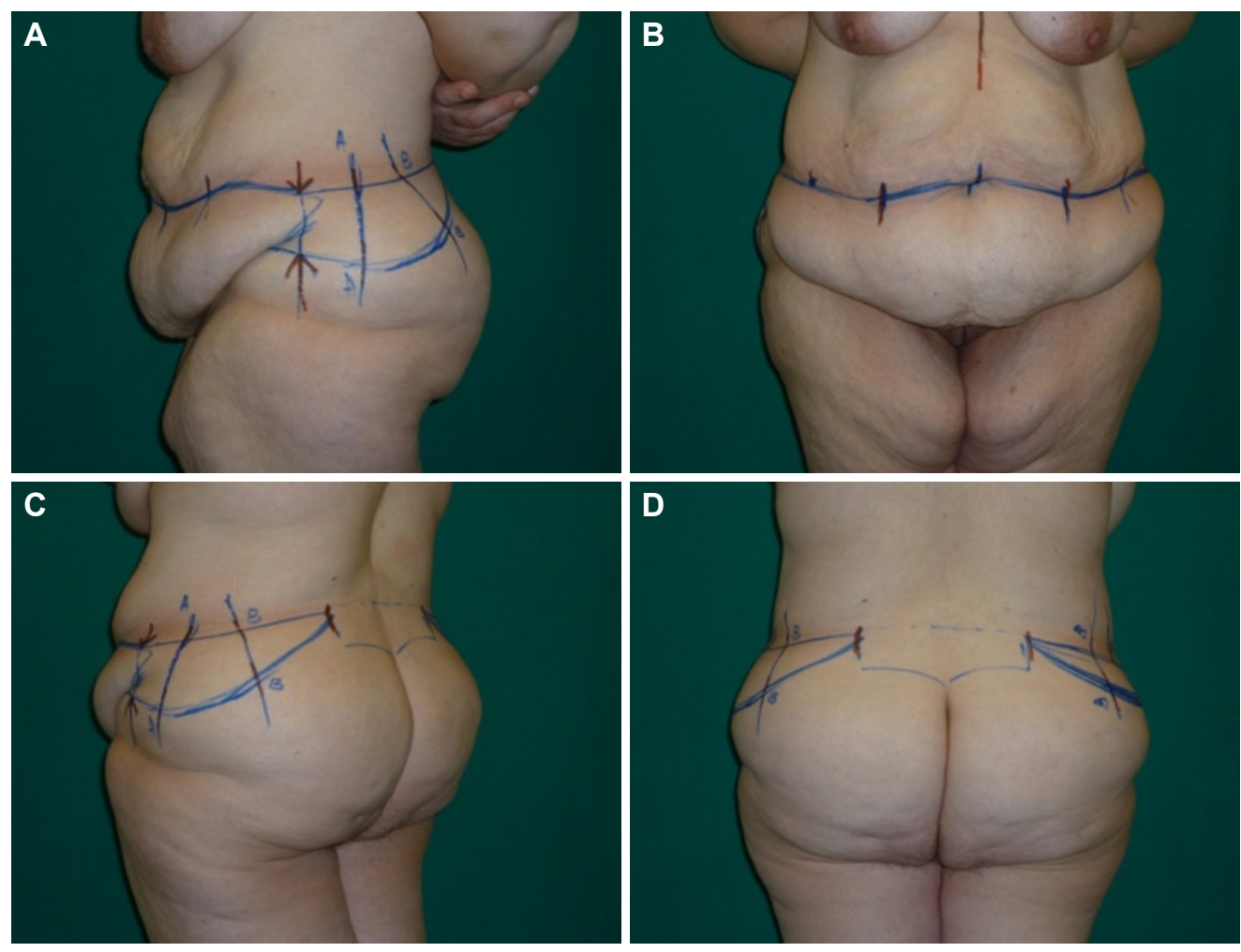

Figure 1: (A) Anterior pre-operative marking, arrows illustrate the border of the extension of abdominoplasty; (B) the upper flap of adipocutaneous excess marked; (C) extension of the incision line dorsally; (D) posterior pre-operative marking, in evidence the pre-sacral area non-interested by incision lines

be marked for the correct alignment of the upper and lower flaps during the suture.

\section{Surgical technique}

The patient is anaesthetised and then placed in prone position. Pressure sore protections are placed under shoulders, knees and ankles. The patient is prepared from scapula to buttocks with povidoneiodine. Skin and subcutaneous soft tissues are incised following the preoperative markings to the lumbar fascia without undermining of the non-resected tissues. Haemostasis is carefully performed by electrocautery. After the excision of the adipocutaneous tissue, two drains are placed. Three layer closure is performed: Vicryl 2/0 (Ethicon Inc, Somerville, New Jersey) for fascia superficialis, Monocryl 3/0 (Ethicon Inc, Somerville, New Jersey) for the deep dermis and Monocryl $4 / 0$ for endodermic suture.

Then the patient is placed in the supine position; skin and subcutaneous tissues are incised down to the anterior abdominal wall fascia respecting the preoperative markings. Umbilicus is isolated and preserved and the flap is elevated to the chest and the xiphoid area. Adipocutaneous excess is removed by a flute mouthpiece incision from the subcutaneous tissue to the superficial fascia. Plication of the muscular fascia is performed with a resorbable suture whenever is needed. The navel is externalized, and two additional drains are placed in the anterior trunk. The surgical wound is closed again in three levels, as in the dorsal incision.

\section{Postoperative care}

All patients received compression stockings and daily prophylactic low-molecular-weight heparin subcutaneously, until 1 week after discharge. The patients were mobilized from the first day after surgery. Antibiotics were administered intravenously during the surgery and continuedorally until discharge. Drains were removed after 4-5 days.

\section{Follow-up}

The patients were discharged after a few days and followed up at 15 days, 1, 2, 3 and 6 months and 1 year, or more frequently in the presence of complications.

\section{RESULTS}

We performed the extended abdominoplasty technique on 21 post-bariatric patients from September 2014 to November 2015 and circumferential abdominoplasty or torsoplasty on 21 postbariatric patients during the same period. 

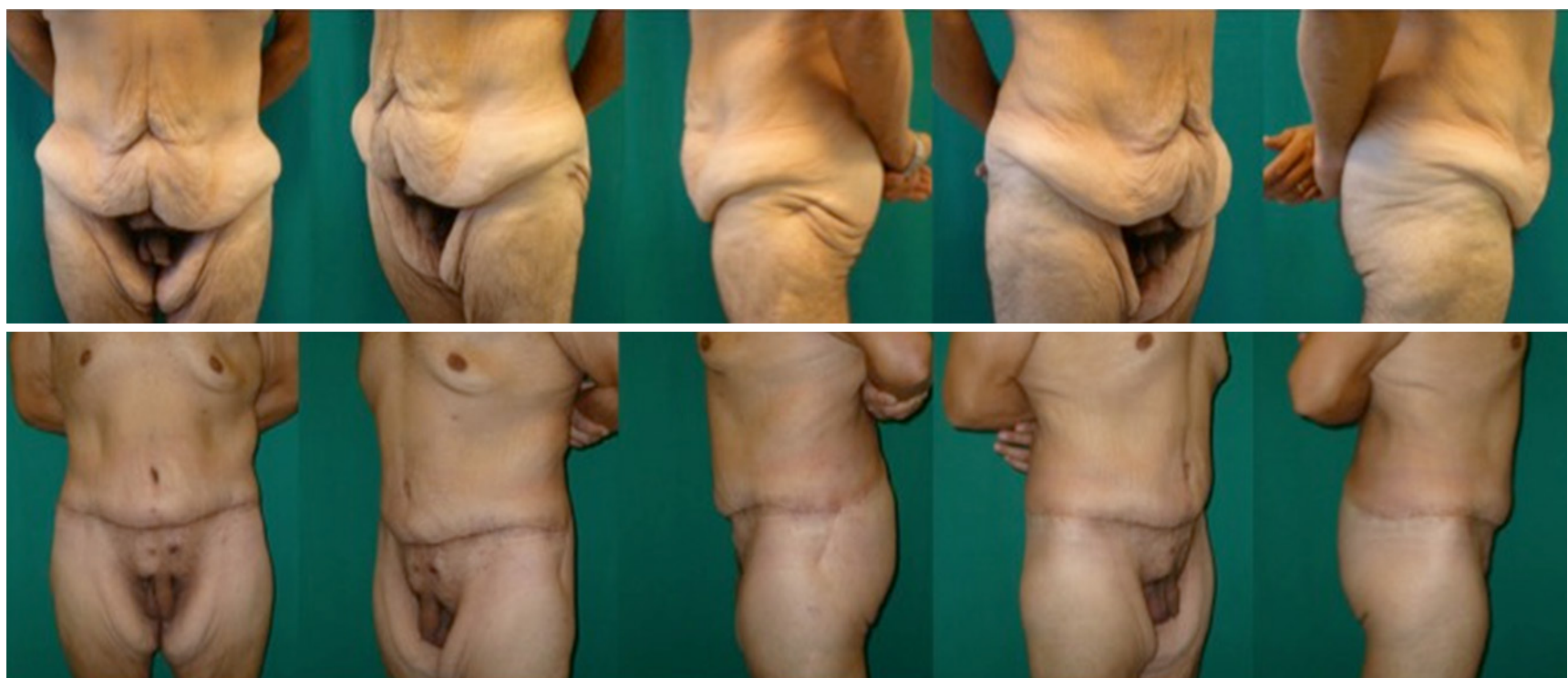

Figure 2: A male patient who underwent vertical banded gastroplasty. Weight loss: $115 \mathrm{~kg}$, from 200 to $85 \mathrm{~kg}$. Upper row, from left to right: pre-operative frontal view, left $2 / 3^{\circ}$ view, left lateral view, right $2 / 3^{\circ}$ view, right lateral view. Lower row, 8 months after surgery (extended abdominoplasty), from left to right: post-operative frontal view, left $2 / 3^{\circ}$ view, left lateral view, right $2 / 3^{\circ}$ view, right lateral view
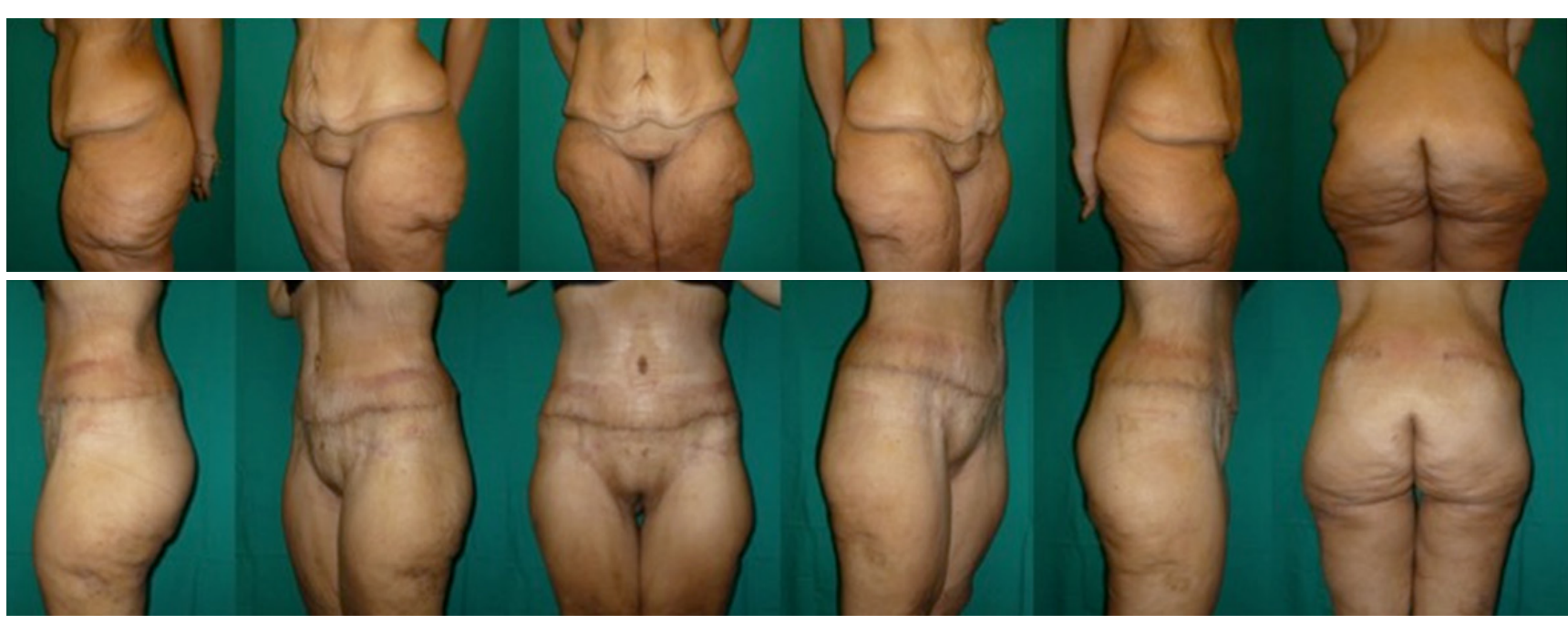

Figure 3: A female patient who underwent vertical banded gastroplasty. Weight loss: $130 \mathrm{~kg}$, from 198 to $68 \mathrm{~kg}$. Upper row, from left to right: left lateral view, left $2 / 3^{\circ}$ view, pre-operative frontal view, right $2 / 3^{\circ}$ view, right lateral view, back view. Lower row, 8 months after surgery (extended abdominoplasty), from left to right: left lateral view, left $2 / 3^{\circ}$ view, pre-operative frontal view, right $2 / 3^{\circ}$ view, right lateral view, back view

Eight males [Figure 2] and 13 females [Figures 3 and 4] underwent extended abdominoplasty. The mean age was 46.8 years (30-63 years), and the average weight loss after bariatric surgery was $69.4 \mathrm{~kg}(28-115 \mathrm{~kg})$. The average BMl at the time of surgery was $28.6 \mathrm{~kg} / \mathrm{m}^{2}$. Mean weight of skin and fat tissue removed was $3,430 \mathrm{~g}$ $(1,750-8,960 \mathrm{~g})$, mean operative time was $3 \mathrm{~h}$ and $30 \mathrm{~min}$ ( $2 \mathrm{~h}$ and $15 \mathrm{~min}-5 \mathrm{~h}$ ) and the mean peri-operative blood loss was $628.6 \mathrm{~mL}$. The patients remained hospitalized for 7.8 days, while the mean follow-up was 14 months.

Seven males and 14 females underwent torsoplasty. The mean age was 45.2 years (30-61 years), and the average weight loss after bariatric surgery was $61.8 \mathrm{~kg}$
(26.5-108 kg). The average BMl at the time of surgery was $27.3 \mathrm{~kg} / \mathrm{m}^{2}$. Mean weight of skin and fat tissue removed was $3,460.9 \mathrm{~g}(1,780-8,930 \mathrm{~g})$, mean operative time was $4 \mathrm{~h}$ and $30 \mathrm{~min}(2 \mathrm{~h}$ and $45 \mathrm{~min}-6 \mathrm{~h}$ and $20 \mathrm{~min}$ ) and the mean peri-operative blood loss was $1,085.4 \mathrm{~mL}$. The patients remained hospitalized for 12.5 days, while the mean follow-up was 14 months.

The comparison between extended abdominoplasty (ex) and torsoplasty (tp) gave the following results regarding blood loss (ex: $628.6 \mathrm{~mL}-\mathrm{tp}: 1,085.4 \mathrm{~mL}, P=0.049$ ), transfusion rate (ex: $0 \%$-tp: $27.3 \%$ ), operation length (ex: 3 h 30 s-tp: 4 h 30 s, $P<0.001$ ) and hospitalization days (ex: 7.8-tp: 12.5, $P=0.002$ ) [Table 2]. 


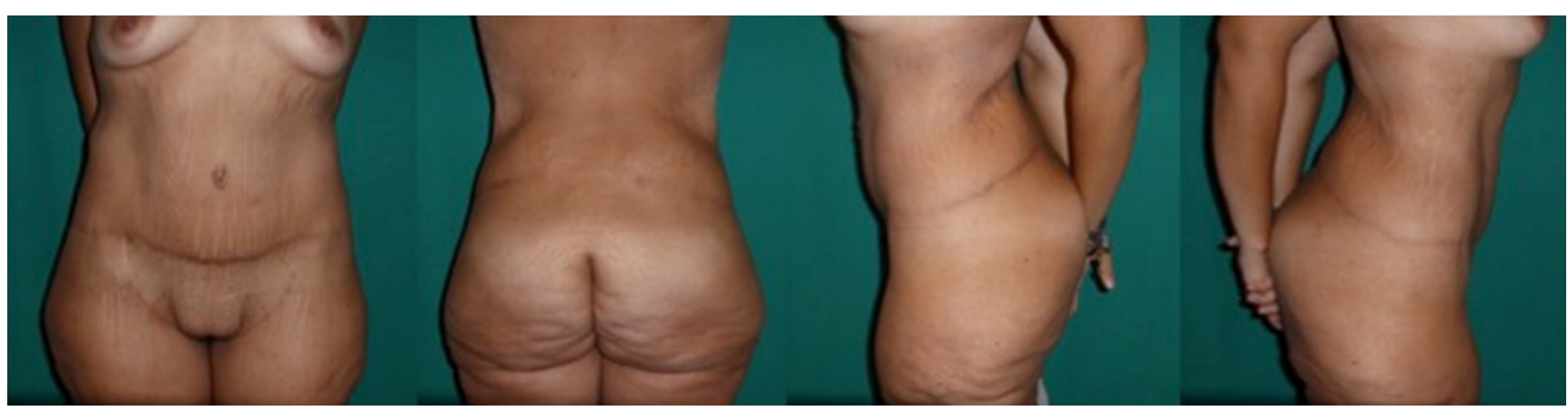

Figure 4: Patient presented at Figure 3, 2 years after surgery. From left to right: pre-operative frontal view, back view, left lateral view, right lateral view

Table 2: Comparison between extended abdominoplasty technique and traditional torsoplasty

\begin{tabular}{lcc}
\hline Characteristics & Extended abdominoplasty & Torsoplasty \\
\hline Excisedtissue, g & 3,430 & $3,460.9$ \\
Blood loss, $\mathrm{mL}$ & 628.6 & $1,085.4$ \\
Trasfusion rate, \% & 0 & 27.3 \\
Operation lenght & $3 \mathrm{~h} 30 \mathrm{~s}$ & $4 \mathrm{~h} 30 \mathrm{~s}$ \\
Hospitalization time, days & 7.8 & 12.5 \\
\hline
\end{tabular}

Peri and postoperative bleeding led to three cases of anaemia necessitating blood transfusions (14.3\%) in the second group; no blood transfusion was needed in the first group.

No other major complications occurred during the postoperative period in both groups, there was no need to drain hematoma or seroma, patients were mobilized during the first postoperative day and were discharged without drains.

Only 5 cases of superficial cutaneous necrosis occurred on the bisiliac suture line, 2 in the first group and 3 in the second group, solved with local dressings in less than 3 weeks.

Patients were uniformly pleased with their results: $90 \%$ of them were very satisfied, whereas $10 \%$ graded their results as satisfactory.

\section{DISCUSSION}

The National Institutes of Health Consensus Conference stated in 1991 "only surgery has proven effective over the long term for most patients with clinically severe obesity". This statement was confirmed and updated in 2004, by the American Society for Bariatric Surgery (recently renamed as the American Society for Metabolic and Bariatric Surgery). ${ }^{[13]}$ The number of bariatric surgery procedures has increased steadily since then and, as a result, the number of massive weight loss patients seeking body-contouring procedures has considerably grown. The redundant excess skin interferes with fitting clothing, physical and sexual activity, hygiene, and it can frequently cause recurrent bouts of infection.

The post-bariatric patient represents a challenge for plastic surgeon. Although post-bariatric bodycontouring procedures are generally associated with high rates of patient satisfaction, the surgeon has to face the negative impact of postoperative complications. The post-bariatric surgery population appears to be at higher risk compared to patients who are not obese. ${ }^{[14]}$

Arthurs et al. ${ }^{[15]}$ found that pre-panniculectomy BMI was the most important factor that independently predicted postoperative complications after a panniculectomy; meaning that post-bariatric surgery population is at higher risk compared to non-obese patients. Patients with a BMI greater than $25 \mathrm{~kg} / \mathrm{m}^{2}$ are at nearly three times the risk of postoperative wound complications. Other important risk factors for complications are nutritional deficiencies, smoking, venous varicosities, and poor quality orinelastic tissues.

To obtain the best outcomes, a comprehensive perioperative approach is required. Proper patient selection, carefully considered surgical timing and the choice of the surgical technique are fundamental to avoid complications.

There are many anatomical regions that massive weight loss patients would like corrected: redundant flank and abdomen, hip rolls, breasts, arms, buttocks and thigh ptosis. For this reason body contouring is generally not considered as a single stage procedure.

Among all the body contouring procedures, abdominoplasty has a crucial role in body image recovery. But the results, even in the most extensive form of abdominoplasty are usually suboptimal because the back and lateral flank deformities are not considered.

To address the circumferential nature of the skin excess in these patients, various surgical techniques 


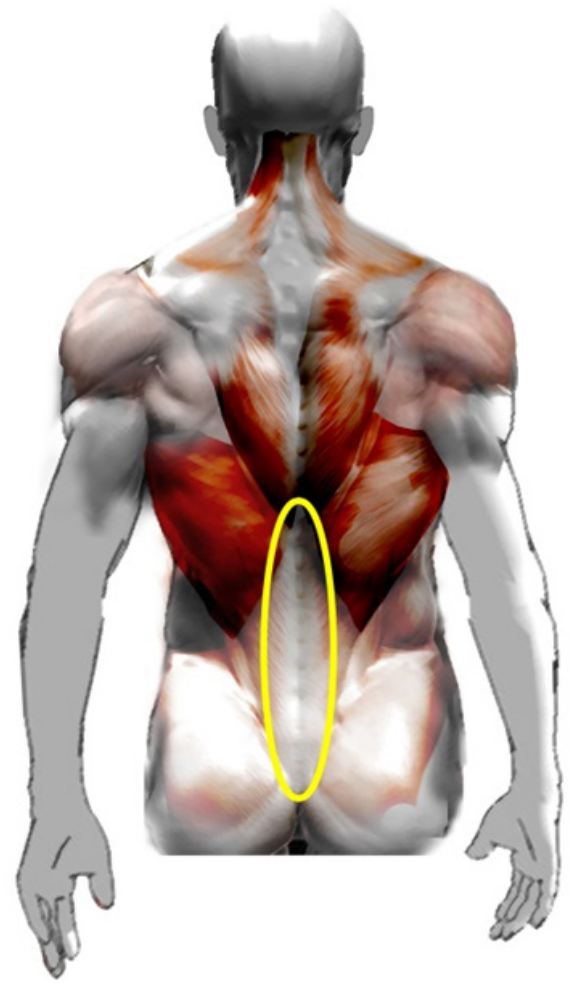

Figure 5: The median dorsal area. In this anatomical district, there is a fascial-aponeurotic tissue, rich in vessels, with skin and subcutaneous firmness

were developed. Circumferential torsoplasty was first described in1960 as the "beltlipectomy" by GonzalezUlloa. ${ }^{[16]}$ His technique involved anterior and posterior midline vertical wedge. Baroudi ${ }^{[17]}$ described a similar technique but without the wedge resection. In 1991 Lockwood $^{[18]}$ described the superficial fascial system of the torso and extremities, and its use in high-tensionlateral closure in the transverse flank-thigh-buttock lift. In 1996 Hunstad $^{[19]}$ described a combined technique of circumferential torsoplasty and liposuction.

In 2002, Pascal and Le Louarn ${ }^{[20]}$ proposed a new concept in the circumferential abdominoplasty: body lift with high lateral tension, creating a dermal flap for the suspension of the buttocks and trochanteric regions.

Belt lipectomy is also known as torsoplasty, circumferential torsoplasty, circumferential lipectomy and panniculectomy. This body contouring procedure is associated with a high rate of postoperative complications. The literature reports a rate of complications ranging from $17 \%$ to $50 \%$.

Seroma is the most frequent complication. It commonly occurs in the posterior region, which is a well-known region for seromas after back surgery.

To minimize complications and hospitalization time, we propose a modified approach to the traditional circumferential torsoplasty, described by Mejia and Cárdenas Castellanos ${ }^{[12]}$ as "extended abdominoplasty" in massive-weight-loss patients.

Compared to traditional torsoplasty the extended abdominoplasty technique preserves the median dorsal area from surgical trauma. This area contains a fascial-aponeurotic tissue, rich in vessels, with skin and subcutaneous firmness [Figure 5], which is at higher risk of bleeding and less involved in theptosis processes. The advantage of avoiding this area is the reduction of intraoperative bleeding, operative time and hospitalization days.

Despite the limited number of cases, in our experience, the comparison between extended abdominoplasty and torsoplasty gives encouraging results regarding blood loss, transfusion rate, operation length and hospitalization days. We had no cases of seroma formation and no other major complication. We reported 5 cases of superficial cutaneous necrosis occurring on the bisiliac suture line, which was managed with local dressing changes for less than 3 weeks. As described in the result section, data analysis supports this hypothesis but the small number of patients limits its significance.

This procedure allows a better distribution of loose tissue after removal of the excess from the flanks. It permits narrowing of the waistline and suspending the skin of the gluteal area without stretching the buttock crease. Compared to the traditional torsoplasty, the aesthetic result is better considering the shorter size of the scars. Patients happily accept the perspective of a shorter scar.

In conclusion, this study presents the results of the use of the extended abdominoplasty in post-bariatric patients. According to the results, this technique allows a reduction in blood loss, operative time and hospitalization days, and consequently leading to less complications and costs.

We believe that extended abdominoplasty is a viable alternative to torsoplasty in selected patients presenting with a severe adipocutaneous circumferential laxity, as occurs in post-bariatric massive weight loss patients.

\section{Authors' contributions}

Manuscript's concept and design: M.A. Bocchiotti, S. Bruschi Literature search: E.A. Baglioni

Data acquisition and analysis: L. Spaziante Manuscript preparation, editing and review: E. Ruka 
Financial support and sponsorship

None.

\section{Conflicts of interest}

There are no conflicts of interest.

\section{Patient consent}

Obtained.

\section{Ethics approval}

The study was approved by the ethics committee of our institution and was performed in accordance with the ethical standards laid down in the 1964 Declaration of Helsinki and its later amendments.

\section{REFERENCES}

1. Eurostat. Overweight and obesity-BMI statistics-Statistics Explained. 2017. Available from: http://epp.eurostat.ec.europa.eu/statistics explained/index.php/Overweight_and_obesity_-_BMI_statistics. [Last accessed on 16 Apr 2017].

2. Buchwald H, Avidor Y, Braunwald E, Jensen MD, Pories W, Fahrbach K, Schoelles K. Bariatric surgery: a systematic review and meta-analysis. JAMA 2004;292:1724-37.

3. Martínez Y, Ruiz-López MD, Giménez R, Pérez de la Cruz AJ, Orduña R. Does bariatric surgery improve the patient's quality of life? Nutr Hosp 2010;25:925-30.

4. Picot J, Jones J, Colquitt JL, Gospodarevskaya E, Loveman E, Baxter L, Clegg AJ. The clinical effectiveness and cost-effectiveness of bariatric (weight loss) surgery for obesity: a systematic review and economice valuation. Health Technol Assess 2009;13:1-190, 215-357, iii-iv.

5. Maggard MA, Shugarman LR, Suttorp M, Maglione M, Sugerman HJ, Livingston EH, Nguyen NT, Li Z, Mojica WA, Hilton L, Rhodes S, Morton SC, Shekelle PG. Meta-analysis: surgical treatment of obesity. Ann Intern Med 2005;142:547-59.
6. Schauer PR, Burguera B, Ikramuddin S, Cottam D, Gourash W, Hamad G, Eid GM, Mattar S, Ramanathan R, Barinas-Mitchel E, Rao RH, Kuller L, Kelley D. Effect of laparoscopic Roux-en-Y gastric bypass on type 2 diabetes mellitus. Ann Surg 2003;238:467-84.

7. Carwell GR, Horton CE Sr. Circumferential torsoplasty. Ann Plast Surg 1997;38:213-6.

8. Shermak MA, Rotellini-Coltvet LA, Chang D. Seroma development following body contouring surgery for massive weight loss: patient risk factors and treatment strategies. Plast Reconstr Surg 2008;122:280-8.

9. Fraccalvieri M, Datta G, Bogetti P, Verna G, Pedrale R, Bocchiott MA, Boriani F, Obbialero FD, Kefalas N, Bruschi S. Abdominoplasty after weight loss in morbidly obese patients: a 4-year clinical experience. Obes Surg 2007;17:1319-24.

10. Vico PG, De Vooght A, Nokerman B. Circumferenzial body contouring in bariatric and non-bariatric patient. J Plast Reconstr Aesth Surg 2010;63:814-9.

11. Hunstad JP, Repta R. Extended abdominoplasty. In: Hunstad JP, Repta R, editors. Atlas of abdominoplasty. Philadelphia: Saunders Elsevier; 2009. p. 75-7.

12. Mejia JA, Cárdenas Castellanos YA. Extended abdominoplasty: application and new classification system for abdominoplasty Aesthetic Plast Surg 2012;36:278-84

13. Buchwald H; Consensus Conference Panel. Bariatric surgery for morbid obesity: health implications for patients, health professionals, and third-party payers. J Am Coll Surg 2005;200:593-604.

14. Staalesen T, Olsén MF, Elander A. Complications of abdominoplasty after weight loss as a result of bariatric surgery or dieting/ postpregnancy. J Plast Surg Hand Surg 2012;46:416-20.

15. Arthurs ZM, Cuadrado D, Sohn V, Wolcott K, Lesperance K, Carter P, Sebesta J. Post-bariatric panniculectomy: pre panniculectomy body mass index impacts the complication profile. Am J Surg 2007;193:56770.

16. Gonzalez-Ulloa M. Belt lipectomy. Br J Plast Surg 1960;13:179-86.

17. Baroudi R. Body sculpturing. Clin Plast Surg 1984;11:419-43.

18. Lockwood TE. Superficial fascial system (SFS) of the trunk and extremities: a new concept. Plast Reconstr Surg 1991;87:1009-18.

19. Hunstad JP. Body contouring in the obese patient. Clin Plast Surg 1996;23:647-70

20. Pascal JF, Le Louarn C. Remodeling bodylift with high lateral tension. Aesthetic Plast Surg 2002;26:223-30. 